\title{
THE FACEBOOK PAGES OF PHILIPPINE PRESIDENTIAL CANDIDATES 2016: DISCOURSE ON NETWORK SOCIETY'S POLITICAL VOICE AND LEGITIMACY
}

\author{
Cecilia Fe L Sta Maria-Abalos
}

University of the Philippines Baguio

\begin{abstract}
The "network society," as located in the net space, is currently being used for varied political agenda in the Philippines and has gained political power for its users in the disbursement of information, raising political opinions and possessing the capacity to unify a political stance. With the coming Presidential election in the Philippines, the net space is once again being utilized to deliver political platforms of the candidates which may influence greatly the turn-out of the election. Given the current trend in the net space, this paper is not exactly about who wins the presidential election, but more so about the net space and the "network society" that focuses on this primary question: How is political opinion being shaped? This paper is a reading of the Facebook pages of Philippine Presidential candidates for 2016. Textual and discourse analyses as methods used to elaborate on: network centre and de-centre, social morphology and personalization of politics. Providing a redefinition of communication, this paper then provides the inextricable links between the network society's identity, power and culture as it exacerbates discussions on political voice and political legitimacy in the net space.
\end{abstract}

Keywords: social media, political communication, Network Society, Philippine Presidential Elections 2016

\section{INTRODUCTION}

This coming May 9, 2016, the Filipino people will be voting for its 16th President. Filipinos aged 18 above will be selecting from this list of official Presidential candidates:

Jejomar Binay - POLITICAL PARTY: UNO United Opposition and the current Vice President of the Philippines

Rodrigo Duterte - POLITICAL PARTY: PDP Laban and the current Mayor of Davao City

Grace Poe- POLITICAL PARTY: INDEPENDENT and the currently serving as Senator.

Mar Roxas - POLITICAL PARTY: LP- Liberal Party and currently the Department of Interior and Local Government Secretary

Miriam Santiago - POLITICAL PARTY PEOPLE'S REFORM PARTY and currently serving as Senator

Campaign season in the Philippines has always been colourful and all Filipinos are usually glued to varied media types: TV, radio, newspapers, etc., watching and listening to the candidates' platforms. If not, varied face-to-face communication is conducted, from formal public debates and forums to informal and lay discussions.

Year 2016 will not only bring to light the track of the country's state when a new President assumes the position but what also needs to be examined further is the re-shaping of political opinions among Filipino voters who are now engaged in a new form and space of communication that is pivotal in the construction

of political opinion. This year is not only crucial for the change of political hands in the country but more so in the shift of communication access and use of

Corresponding Author: fayestamaria@gmail.com 
many Filipinos that will set a precedent in shaping the new political public sphere that has re-located to the net space.

Moving away from the usual mode of visibility in television, radio and print, what is being rampantly used as source of information is the net space. Blogs, online news, etc. are among the online spaces explored by Presidential candidates as a vehicle for disbursing information about themselves and their political platforms. Because Filipinos are now relying greatly on information sourced from the net, Presidential candidates have found a faster, cheaper and more accessible means of communicating to the public: the Social Networking Sites (SNS), specifically the Facebook. With visibility in the Facebook, we are now witnessing a trend in the way political opinion is being shaped.

This paper then takes primary concern on media visibility of Philippine Presidential candidates in the net space, specifically in the Facebook. A content analysis of their Facebook pages, Presidential candidates' posts, links, comment threads, etc. were monitored from the official filing date of candidacy in October 2016 until February 28, 2016. The reading of their Facebook pages enabled the elaborations on the shaping of political opinions of individual Facebook engagers, expounding on the following:

The current space of the public sphere in relation to the shift in the use of space

Re-definition of communication based on its salient features in the online space that is contributory to the shaping of political opinion

Re-construction of citizens' identity, power and culture, and,

Personalization of politics in the net space in relation to political voice and political legitimacy in the net space

\section{The New Public Sphere}

Habermas (1996, cited in Castells, 2008, p. 78) says that "between the state and society lies a public sphere, 'a network for communicating points of view." As part of a society, citizens essentially should form a public sphere that can serve as an arena for communicating political issues in order to make a strong political stance to "articulate their autonomous views to influence political institutions in society" (Castells, 2008). The public sphere, because it is "between the state and society," (2008) acts as a mediating body that provides check and balance in the implementation of certain political policies. Key elements imperative in the forming of a public sphere are: space and communication exchange and flow. The space acts as the venue or arena for individuals to conglomerate in order to communicate freely, exchanging varied points of view on political issues in order to arrive at a rational decision that will be articulated and hopefully to influence political policy making and implementation.

All Presidential candidates are currently visible in the online space, through the Facebook, which presents a different set of features. The net space, which is not bounded by a specific political territory, is now "constituted around a media system" (Castells, 2008). In this shift then, this media system, en sans the net space, possess the "capacity of social movements to change the public mind" (2008) but is very much dependent on the kind of political debate and discussion emanating from the net space. Moving away from the Information Age, Castells (2000) explains that the current state of society revolves around technological information that is located in the net space. Constituted by a "paradigm around microelectronics-based information/communication technologies" (2000, p. 5) wherein individuals are networked and the dominant activities circumvent around information as space proviso.

The net space has produced a social group who can be active social actors that are bounded by information. It has constructed a global structure that is not bounded by national or political territorial time and space. It may be owned by certain administrators and net providers but the massive use of individuals and groups who are "networked" or connected through access of common information, albeit a common locale and time, may possess the power to influence political opinion. The net space then has produced a new public sphere. 


\section{Re-definition of Communication}

\section{Hypertext}

What strengthens this new public sphere is the use of symbolic communication or hypertext as means for exchange and interaction. As part of their binding communication culture, net users are mediumoriented because knowledge and information is located in the net space as a "medium wherein technology becomes indispensible" (Castells, 2000, p. 14). The medium or the net space is constructed around a set of symbolic codes with images, memes, videos, minuscule comments and dialoguing becomes the net space's form of communication that further strengthens their "shared cultural codes" (2000, p, 21).

\section{Bakit kung sino pa'ng nognog siya pa'ng nagbigay liwanag?}

Hindi po tayo titigil sa ating layunin na makatulong at makapagbigay
ginhawa sa lahat.
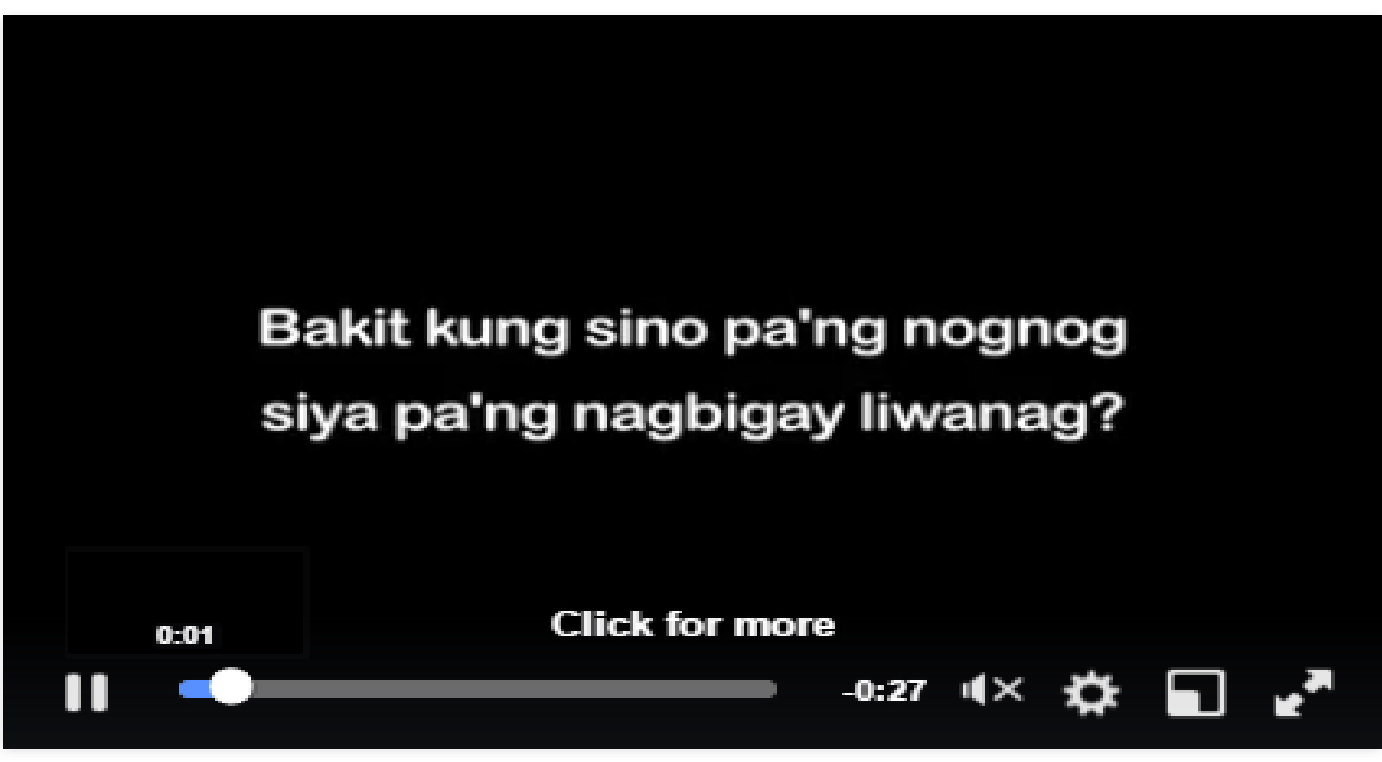

$386 \mathrm{k}$ Views

$(9)$

Ith Like Comment $\Rightarrow$ Share

14,789 people like this.

Top Comments -

1,961 shares

Figure 1. Sample of Hypertext Through A video

Given the space considerations in the net; to cite a few, photos, videos, images and other links become the basis of meaning exchange. Facebook engagers then establish a "cultural meaning" online. As examples, LIKE or SHARE becomes synonymous to agreement and showing of support. Noticeable is that most of the posts with photographs of the candidates or poster-like images tend to earn more number of LIKES and SHARES. Facebook supporters and followers of the Presidential candidates tend to take partiality towards posts that contain less written texts. Given the nature of the net space, accommodations for hypertext become a clear preference and a communication choice. Observing this trend of meaning exchange in the net space shows a trend that sets aside text-heavy and elaborated forms of language because the medium or the net space takes parlance to hypertext, it reconstructs a new social morphology for communication. Reliance to information presented in the net space becomes a 
"social logic [that] becomes that of a competition and struggle for information" (Castells, 2000).

\section{Carolina Navarro Sus,vp ka for 6yrs.bkit dpa ginava lgi nman pagod teachers sa election at sa makkulit n estudyante.. Like - Reply - 2 2- October 15,2015 at 7:13pm}

\section{Arvey Jhune Malanog scientist \\ Like - Reply - October 17, 2015 at 1:29pm}

Rosalyn Mallorca Pamittan ONLY BINAY $\bigcirc$

Like - Reply - 1 - December 24, 2015 at 2:46am

Rosalyn Mallorca Pamittan

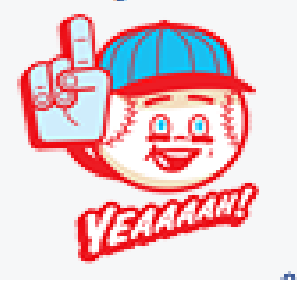

Figure 2. Comments with Memes as Replacement for Worded Texts

Observable in the Facebook pages of Presidential candidates are comment threads utilizing hypertexts. Facebook users tend to reply with comments by posting another image (e.g., heart, facial expression emoticons, and other images). In the net space, words are replaced with images to elaborate on a certain opinion. This is acceptable for Facebook users because they understand such meanings. Communication exchanges then take on a different social norm or communication cues that are different from that in the offline space.

If communication is not through exchange of symbols and images, the threads present a series of comments that attempt to do discussion taking the hypertext as the springboard for information. 


\section{Grace Poe}

November 7,2015

Q

These leaders and I share a commitment to build a society where no Filipino will be left behind, a country where everyone will be able to reap the fruits of economic growth and enjoy life in a safe and progressive environment. Together, there is nothing we cannot achieve for the country \#WalangMaiiwan \#PGP2016

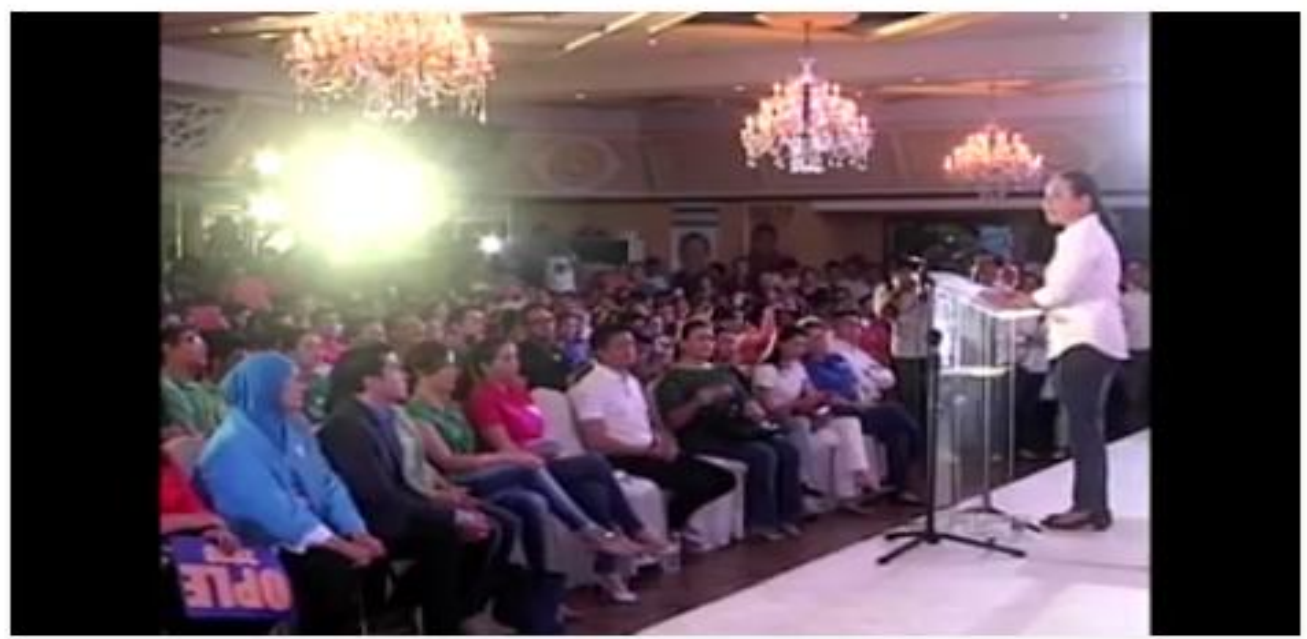

48k Views

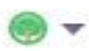

I Like Comment $\Rightarrow$ Share

3,220 people like this.

Top Comments -

- Danica Dawn Caseres Caberte Go, Senator Poe! We believe in your cause a and we are with you all the way! $(-)$

Like - Reply - 341 - November 7,2015 at 10:21pm

Pot Sheenos Lagundi POE till the end. Like - Reply - B 1 - November 8,2015 at 3:03am

2 Amante del Mundo 'Yang si Amando Doronilla, hindi lang naappoint na official ambassador sa Timbuktu-- sa panahon ni Arroyo (sa kabilang ng backing at suporta ni Arroyo) ay nagpuputak-putak ngayon laban sa isang malakas na kandidato sa pagkapangulo na gaya ni Grace Poe.

Sino ang gusto niya, si Binay na maka-People's Republic of China o si Roxas na mahinang lider- laging palpak ang sinasabi?

Like - Reply - November 8,2015 at 7:03am - Edited

FI Gerv Aguilar The nine member tribunal is composed of three Supreme Court justices (Carpio, De Castro, and Associate Justice Arturo Brion) and six senators (Sotto, Villar, Cayetano, Nancy Binay, Bam Aquino, and Loren Legarda) its like an impeachment process.. a number games. carpio already said that grace poe is not natural born citizen.. cayetano also said its easy for her to decide if the DNA test is possitive. im sure $100 \%$ with this people to decide grace poe will be disqualified.. i bet my 100 pesos in my wallet Like - Reply - 1 - November 8, 2015 at 11:58am

Voltaire Balbastro All the way to the States ? Like - Reply - November 9,2015 at 12:22am

Figure 4. Comments Not Related to Main Post 
In Poe's post in Figure 4 that shows a photograph of herself with a statement that says "No Filipino will be left behind" and citing that all Filipinos should be part of economic growth, garnered more than 3,000 likes. Comments posted is not limited to expressions of support. Instead, it became a platform to talk about Poe's citizenship and to bash other candidates.

What is evident in these kinds of Facebook pages is presentation of limited information but with conversations and replies of Facebook users with extreme and nonsensical comments. Because this is primarily used as a source of information for most voters, posts such as these elicits more questions and confusion about information contained in the post and in the thread of comments.

If this is the current direction of communication social morphology, Facebook users then tend to rely solely on the information provided in these pages and are tentatively satisfied with these posts. When a user is on Facebook, he/she is usually surfing other sites that may not have anything to do with the topic being discussed in the page. The liking and showing support and non-support, the comments posted which are usually left unanswered provides limited access to pertinent information that is very much needed in forming a political opinion.

Castells notes that the "predominance of social morphology over social action" may lead to a problematic communication social morphology (2000, p. 16). Considering that this kind of communication is currently happening in the net space, this may be consequential to apathy. The struggle for information in the net space, as limited to hypertext becomes an individual struggle whether to pursue further information with regards to the post or to stop and leave the post and become satisfied with this information. Because the new public sphere is medium oriented, and information presented in the net space becomes the ultimate source, what emerges is the practice of automatically taking in of information without weighing the information presented.

Foucault (1977, in Thompson 2005, p. 39) says that the spread of information in the net space becomes a new training and form of discipline in thinking and processing of information because this space tends to "normalize the power of the gaze". Meaning, what information is available in the new public sphere and the way people communicate with this new kind of social morphology may be actualized in social practice. A social structure built on information and totally reliant to the medium is perceived as dangerous because people tend to take in information that is only available. Though the users may post questions, ample weighing of information, such as, if this information is accurate, thorough, sincere, etc. cannot be wholly provided by the new public sphere. Though users of Facebook may post opinions and questions online, translating it to social action is not an assurance.

Such reliance to hypertext is consequential to the way people will think and formulate their political opinions that is only provided by the overt hypertexts present in the net space. Contextualizing these statements in this paper, Facebook users then, due to their reliance to available information, may actually decide on whose Facebook page provides the most information or the catchiest types of information which may not exactly be logical.

\section{Flow and Spread Resulting to "Equity"}

Castells notes that "networks dissolve centres, they disorganize hierarchy, and make materially impossible the exercise of hierarchical power without processing instructions in the network, according to the network morphological use" (2000, p. 19). Rampant use of hypertext afforded by the flow and spread of communication in the net space tends to diffuse the concept of centre. In the offline space, communication is usually centred by the structuring and forming a "source or authority" that tends to choose the messages or information to be disbursed to the audience. In contrast to the offline space, not everyone is technically reached by the messages disbursed which brings about problems and questions on equity in access to information, type of messages received, selectivity of audience and the source who tends to centralize information.

The shift of the public sphere from the offline space to that of the online space, in a way, remedied this problem by:

1. dissolving the usual concept of the "source," through immediacy in spreading and disbursing information through re-posts, shares and likes 
2. equally viewed and shared hypertext by most Facebook users because they technically see the same posts

3. freedom to comment regardless of class, sex, educational status and the like which cannot be controlled.

Given the number of Likes earned by the Presidential candidates in their Facebook Pages, all of them reached more than 1 million likes. Because this is automated by the Facebook function, this then becomes the number of posts, vis a vis, the number of new sources. Looking at it deductively then, this is the number of re-shares and the chances of spreading information about these candidates.

The net space in itself is "value-free or neutral" (Castells, 2000, p. 16) and is dependent on the communication goals and agenda of its users. In the case of Facebook page used for campaigns, because it is dependent on individual connections and "friendships," re-posts of hypertext in an individual's Facebook page only appears as a post for viewing, unless attached with overt statements of support for the candidate. Thus, the re-posted hypertext of the candidate is viewed by other "friends." This viewing is a covert form of showing support as naturalized by the cultural meaning in the net space.

\section{Communication Goal}

Given the presence of hypertext and the freedom to communicate, the communication goals then become too fluid and flexible for every user making the net space a potent avenue for competition and assertion of socio-political logic. Grossman says that the net space if "designed with care, can offer society the opportunity both to engage more people in the democratic practices and to engage people more directly in new ways... that can offer the chance to empower people" (in Holeton 1998, p. 204). Therefore, if the SNS is controlled properly and with precision, an individual whose socio-political goals are equitable possess that opportunity and chance to engage and influence other users in order to shape certain political policies.

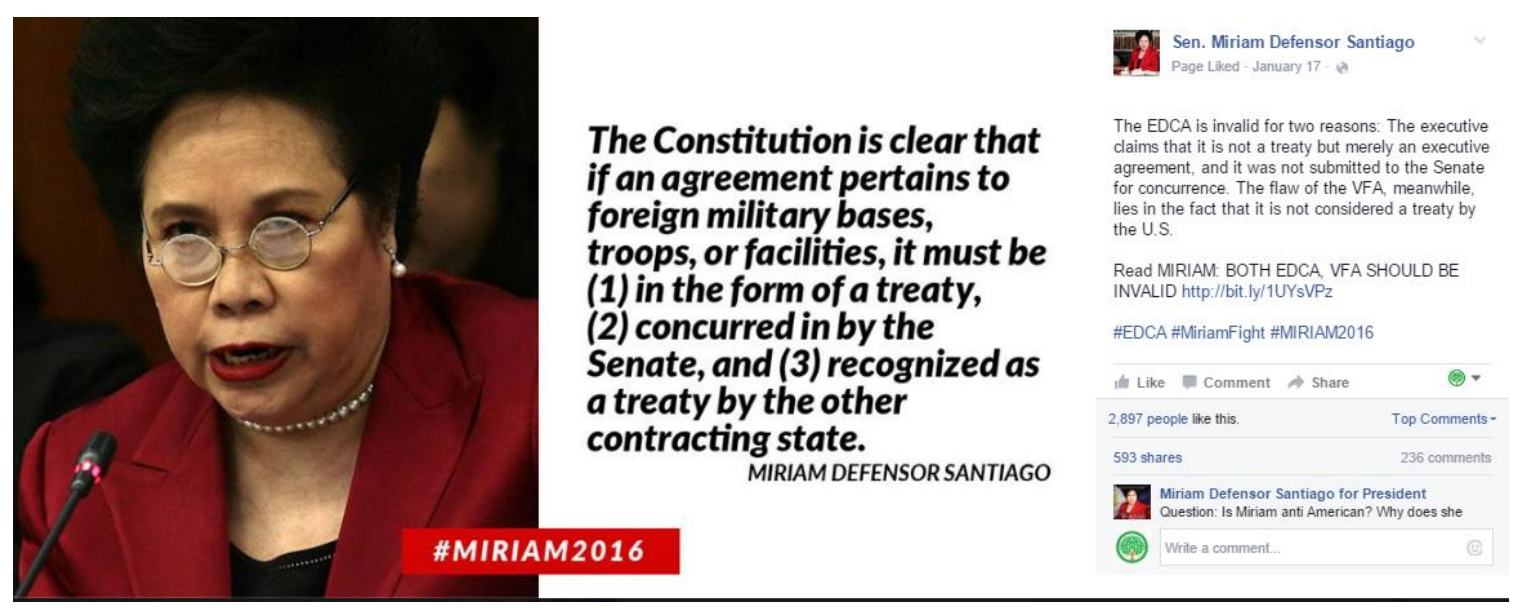

Figure 5. Post of Miriam Defensor Santiago that elicited good arguments

In Santiago's post about the foreign military bases in the Philippines (See Figure 5 above), comments elicited from this post enabled the Facebook users to conduct a good discussion on this issue. Observable is that Santiago's communication goal to conduct exchanges on the issue was achieved. Unfortunately, not all Facebook Pages of Presidential candidates elicited the same results. Katz said that the problem arises because "ideas almost never remain static on the Web...[Information, comments, etc.]. instead, messages are launched like children into the world, where they are altered by the many environments, they pass through, almost never coming back in the same form which they left" (in Holeton, 1998, p. 216). Please See Figure 6 below. 


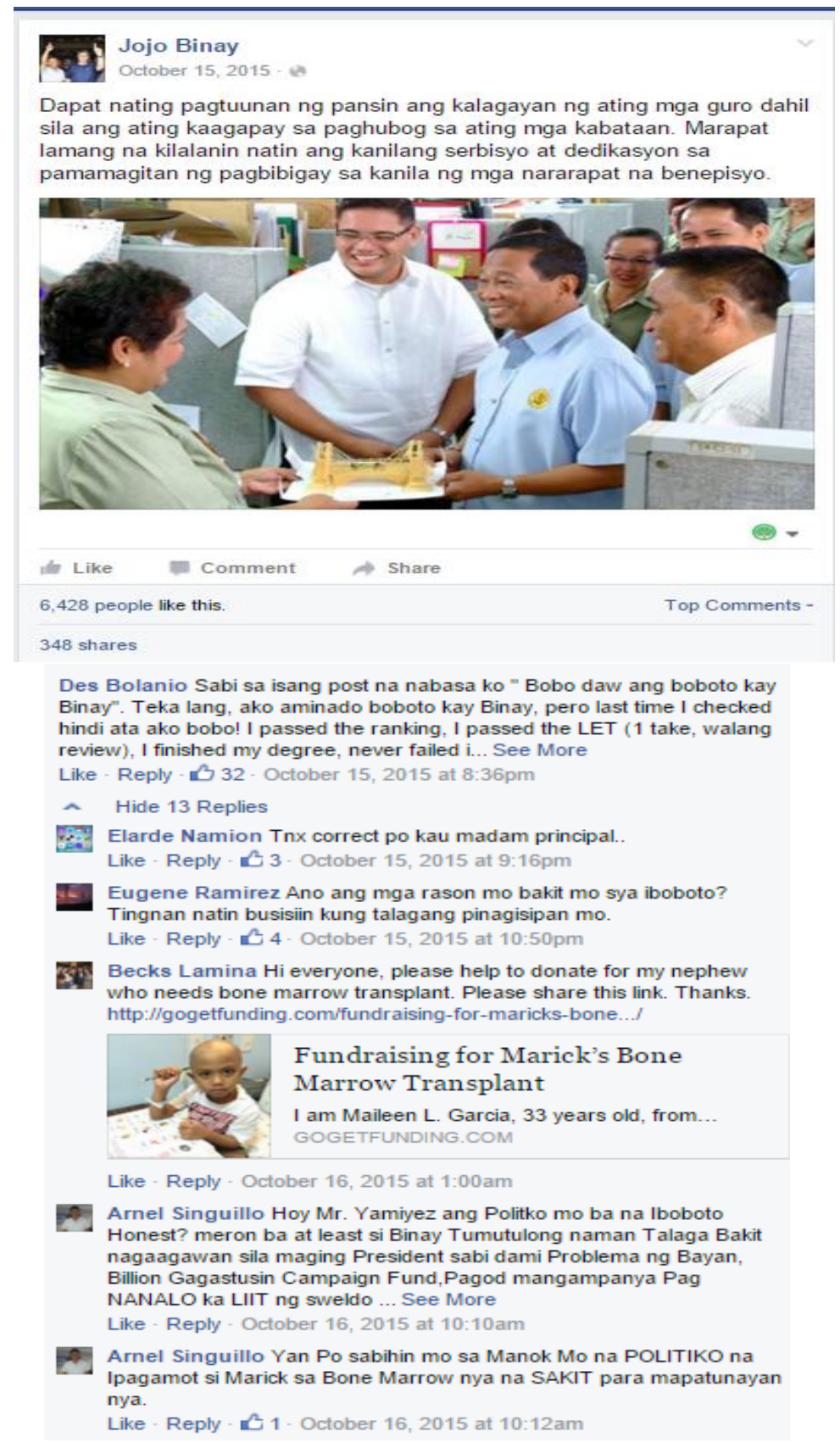

Figure 6. Binay's Post with insertion of a new Communication Goal

In Figure 6 above, Binay is laying down his platform for teachers. Comments ranged from showing support and dislike to the post which presented a nonlinear, non-logical flow of communication. Magnified as well is the insertion of a Facebook user to present another communication agenda by posting a link about a child in need of a bone marrow transplant. Therefore, in launching socio-political campaigns in the net space, communication goals may revert or take into another form, continuously redirecting communication goals that are spreading like wildfire without reaching a lucid consensus, or worse, may contribute to confusion towards reaching a strong and logical political opinion. Katz further elaborates that due to the freedom to communicate as provided in the net space, a new mode of rationalization may occur-that which is composed of "disorganized public discussions" which may result to "confrontation, misinformation, and insults" (in Holeton, 1998, p. 222). This may be consequential to further apathy of other individual users who may become confused and disappointed by the varying information posted online, or worse, a counter social action that may be too difficult to control in the offline space. 


\section{Personalization Politics}

Given the nature of the space for the new public sphere, the shaping of political opinion present in the Facebook pages of the Philippine presidential candidates takes on the form of what Van Aelst, Sheafer and Stanyer (2011, p. 204) refers to as "personalization of politics." This is indicative of "focus on individual politicians as central actors in the political arena, including their ideas, capacities and policies" with two main features: individualization and privatization (Van Aelst, et. al, 2011, p. 204). Individualization is referred to as a "shift in media visibility from political parties to individual politicians or candidates" (2011). Both individualization and personalization focus on the "politician as occupier of a public role to the politician as a private person, distinct from their public role" (Van Aelst, et. al., 2011, p. 204). Currently evidenced in the Facebook pages of the Philippine presidential candidates are the shifting of the normative political structures that separates the candidates from the political parties.

Given the history of political system in the Philippines wherein the political parties shape the structures for running the government, the candidacy and campaign platforms already shows the separation between the candidate and the political party. Upon filing for official candidacy, these candidates posted in their respective Facebook pages announcing their political plans. Though they are connected to certain political parties, the candidates only mentioned them but did not exactly focus on the more cohesive and compounded political stances of their respective parties. This reflects a shift in political system wherein the Filipinos are made to focus on the individual candidate.

The continuing separation of the candidate from the political party or the process of individualization is consequential to the style of political marketing strategy to emphasize the candidate as a person that is devoid of hidden political agenda. Van Aelst, Sheafer and Stanyer point out that the growing trend in the use of media has made the users and potential voters focus “ 'attention on 'personal life' on one hand and the attention on more 'personal characteristics' on the other as two distinct subdimensions" (Van Aelst, et. al., 2011, p. 207).
Looking into the Facebook pages of the Philippine Presidential candidates, posts range from taking on the image as a grandfather, a husband, a loving wife, a daughter, etc. that highlight their varied social roles. Upon posting such highlights, the candidates wishes the Facebook engagers to see them as a person who prioritize their private social roles.

Perceived as a sub-dimension of privatization, in the case of the Presidential candidates' Facebook pages, their personal life and personal characteristics are closely linked. Prominent in the candidates' Facebook pages are also characteristics as a public figure who came from a poor family, an entertainer, and the like. Characteristics of the candidates are posted to create an image, not only as a politician, but more so as an individual with so called good qualities.

A spin-off as well in the Facebook pages as used for campaign is the establishment of direct relationship of the Presidential candidates with the Facebook users. Miriam Santiago utilizes this style very well. Her posts tend to be serious but usually injected with humour. Jojo Binay establishes intimacy with users by presenting his background as poor and how he is usually picked on because of his appearance. Roxas tends to project himself as a person who is rich but likes a simple life. Duterte's courage becomes a focal concern in his pages while Grace Poe establishes intimacy with the users by forwarding her relationship with her father and how being an American citizen is a non-issue because she wants to serve the country. Extrapolating from these posts, one can see, based on the number of likes and shares, these posts appeal greatly to most Filipino voters.

Given the nature of the new public sphere, the "mediated political communication is more personalized" and the argument on this now is "based on degree and not the kind" ((Van Aelst, et. al. , 2011, p. 205). The net space then becomes an available venue for political marketing, in which socio-political issues are not the main message being debated upon, but it becomes the person carrying the socio-political issue. Therefore, the struggle for political advantage in the net space is the struggle for a personality that will be palatable for potential voters.

In the case of these candidates, an individual who likes their page provides the semblance to the 
individual user's account that he/she is connected and associated to the candidate. Acknowledging the fact that individuals by nature wish for a semblance of connection with others to enrich one's social life, the Facebook then becomes a powerful tool for establishing this kind of connection with potential voters.

To map the concept of political opinion shaping as reflected in the use of Facebook by Philippine Presidential candidates, the most salient factor is the use of the medium which is the online space that re-shaped the public sphere and re-constructed communication through the use of hypertext, relegated the communication flow and spread resulting to a very fluid communication goal. Given the alterations in communication process present in the net space, what is emphasized is the personalization of politics that continuously shape the political opinions of net users. Please see Figure 7 below.
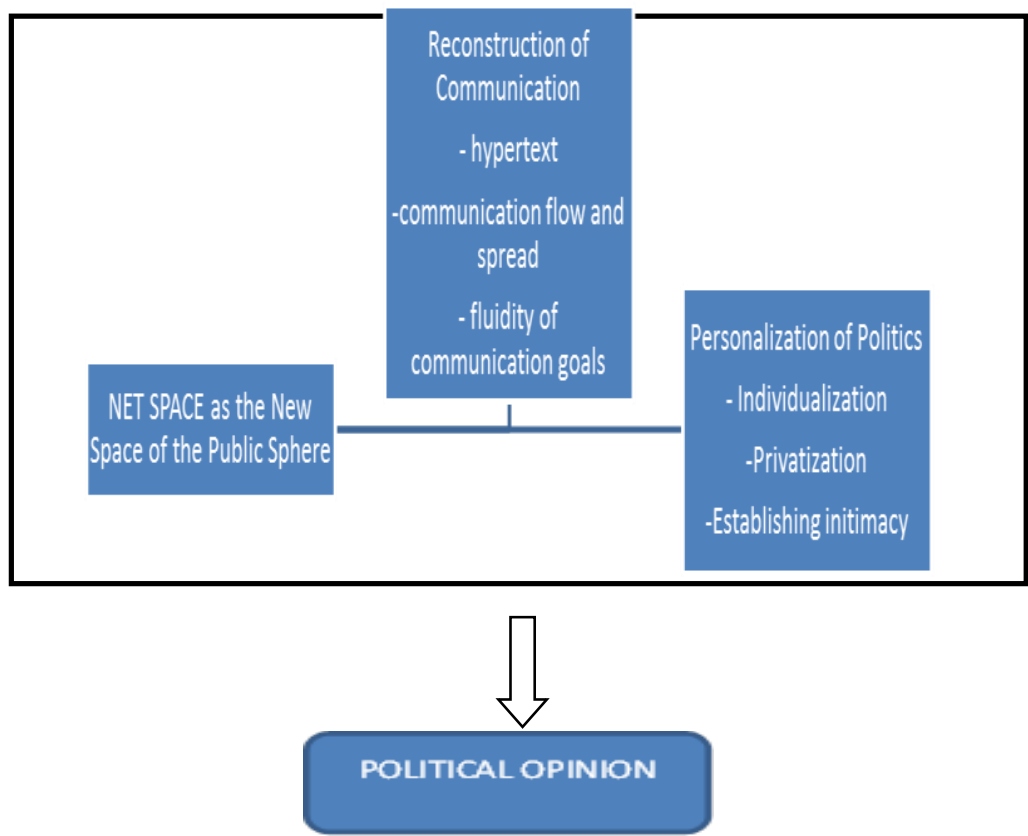

Figure 7. Concept Map of Political Opinion in the Facebook

\section{Shape of Political Opinion: Culture, Identity and Questions on Political Legitimacy}

The shape of political opinion evident in the Facebook pages of Philippine presidential candidates reflects a new public sphere that is medium and visually oriented. Emanating from the use of the net space is the culture of "mediated visibility that is not just a vehicle through which aspects of social and political life are brought to the attention of others but also has become a principal means by which social and political struggles are carried out" (Thompson, 2007, p. 49). The new public sphere is constructed massively by technology that is bombarded by information and messages that compete for visibility and validation. Information in the online space struggles for visibility in the attempt to dominate the net space through appearance and capacity for spreading.
Thompson explains the bombardment of information as: $(2007$, p. 48$)$
"more intensive in the sense that the sheer quantity of information flow is much greater than before... and more extensive in the sense that the range of individuals who are drawn into these networks of communication are capable of receiving and responding immediately" (2007).

Consequential to the information struggle, the following may happen:

- tendency for information to be shared and re-posted even if these messages are vague and lacks elaboration which may be accepted as true, and/or,

- chances wherein even if the messages are important, they may be neglected. 
These kinds of interruption in information and discussion tend to convolute the issues that need attention and elaboration vital in making a political opinion. Moreover, too many information, compounded by numerous comments from other users, the net space becomes a battleground for the most attractive information with the strongest comments.

What is currently proliferating is the "culture of mediated visibility", (Thompson, 2005, p. 49) due to the presence of all kinds of information in the online space. This can be contributory to the political packaging of the candidate but may also serve as counter-productive. Too much exposure to messages and information that adhere to personalization politics emanate a concept of "politics of trust" (2005, p. 49). The candidates may appear to be more human and connected to the user but the eroding of public and private boundaries may become the sole basis for choosing and voting. This kind of erosion of the public and private boundaries bank on personality, credibility and integrity of the candidate as an individual divorced from his/her political work. The cornerstone of politics then take focal concerns on the candidate's personality and personal characteristics (i.e., kind, humorous, smart, sympathetic, a good family man or woman, etc.) which is outweighed by his/her political platform. Perceived danger is when the net users learn something about the candidate that questions the projected personality, he/she becomes rendered as unworthy and of low credibility that will spread immediately in the net space.

The permeating culture in the net space that highlights hypertext and information, with parlance to individual characteristics, construct a confusing identity, both for the candidate and the net space users as well. As one is continuously exposed to information the borders between online and offline reality may become blurry. Reliance to information present in the net space is still perceived by potential voters as a struggle for political advantage that may result to ambivalent voters.

The interplay between character of the candidate and his/her own political platforms is not exactly an assurance in gaining political advantage. Because of the saturation of information on the character of the candidate outweighed by the number of information on political platform lead to confusion, which may in turn, increase the population of non-commitment from these potential voters.

This kind of culture and identity, rooted in the medium and information, produces a type of political legitimacy that is totally reliant on information. Thus, information present online becomes a legitimized political opinion but does not exactly translate into social action in the offline space.

\section{CONCLUSION}

Given that public sphere is now located in the net space, communication now has the following features:

- Use of hypertext bringing along with it a communication social morphology that normalizes a certain gaze on political issues

- Rapid information flow and spread that gives a notion of equity in information accessed by users; and the continuous role of net users as authority/source

- Fluid communication goals

The reconstructed communication process has resulted to personalization of politics in the net space that influence greatly the political opinions of its net users. What results from this is the permeation of culture of media visibility in the new public sphere where there is the struggle for information based on presence and validation. Consequential to this is an ambivalent set of Presidential candidate and net users because political legitimacy is now reliant to the medium and information. Therefore, political communication is neither a struggle for political agenda nor political authority but is now the struggle for information saturating the net space.

The new public sphere has now emerged in the Philippines wherein the online space shapes the political opinion based on information present and is being made legitimized by liking and re-sharing. Seeing the trend in the number of likes, the number of comments and re-shares of posts, can we predict who will win in the 2016 Philippine Presidential election? No. As what Castells (2008) says, "the movement of public opinion is made up of turbulences of information." And these turbulences of information have strong chances of confusing potential voters. 


\section{REFERENCES}

Castells, M., 2000, Materials for an Exploratory Theory of the Network Society. British Journal of Sociology. 51(1), 524.

Castells, M., 2008, The New Public Sphere: Global Civil Society, Communication Networks, and Global Governance. Annals,AAPS. 616, 78-93.

Grossman, L., 1998. The Shape of the Electronic Republic. In Holeton, R. (ed.). Composing Cyberspace: Identity, Community and Knowledge in the Electronic Age, edited by R. Holeton. U.S.A.: Mc Graw Hill. 203-213.

Katz, J., 1998. The Netizen: Birth of a Digital Nation. Composing Cyberspace: Identity, Community and Knowledge in the Electronic Age, edited by R. Holeton. U.S.A.: Mc Graw Hill. 214- 225.
Thompson, J., 2005. The New Visibility. Theory, Culture and Society. (22)6, 31-51.

Van Aelst, P. Sheafer, T. and J. Stanyer, 2011. The Personalization of Mediated Political Communication: A Review of Concepts, Operationalizations and Key Findings. Journalism. 13(2),203-220.

Online Sources

Jojo Binay. Date of Access: 10/15/2015-3/1/2016. http://www.facebook.com/JCBinay/infor/?tab=page_info.

Rodrigo Duterte. Date of Access: 10/15/20153/1/2016.https://www.facebook.com/rodyduterte/info/?tab= page_info.

Grace Poe. Date of Access: 10/15/2015-3/1/2016.https://www.facebook.com/sengracepoe/info/?tab=page_inf o.

Mar Roxas. Date of Access: 10/15/2015-3/1/2016. https://www.facebook.com/mar.roxas.official/info/?tab=pag e_info.

Miriam Santiago. Date of Access: 10/15/20153/1/2016.https://www.facebook.com/senmiriam/info/?tab=p age_info. 